\title{
INFLUENCIA DE LAS MISIONES CHILENAS EN LA ESCUELA MILITAR DE CADETES (1907-1916)
}

\section{Resumen}

En 1907, al frente de la Escuela Militar de Cadetes y de la Escuela Naval Nacional, fue colocada la Primera Misión Chilena contratada por el gobierno de Rafael Reyes gracias a las gestiones de Rafael Uribe Uribe y Samuel Ramírez Arbeláez. Tres Misiones más permanecieron en Colombia, hasta 1916, enfrentando diversos obstáculos a su labor. EI presente artículo ubica históricamente dichas Misiones, detalla sus integrantes y enuncia la influencia ejercida sobre los militares y su escuela de oficiales.

Palabras Clave: Misiones chilenas, Ejército de Colombia, Escuela Militar.

\section{INFLUENCE OF CHILEAN MISSIONAS TO THE MILITARY ACADEMY (1907-1916)}

\section{Abstract}

In 1907, to the head of the Military school of Cadets and of the National Naval School, it was placed the first Chilean Mission hired by Rafael Reyes. Up to 1916, three more Missions remained in Colombia facing diverse obstacles to their work. The present article locates historically these Missions, it details its members and it enunciates the influence exercised on the military ones and their school of official.

Key words: Chilean Missions, Colombian army, Military school.

Doctor en Sociologia. Profesor Universidad Pedagógica Nacional, Bogotá. adolfoatehortua@cable.net.co

Texto original recibido: $26-05-08$ y aprobado: $22-07-08$ 


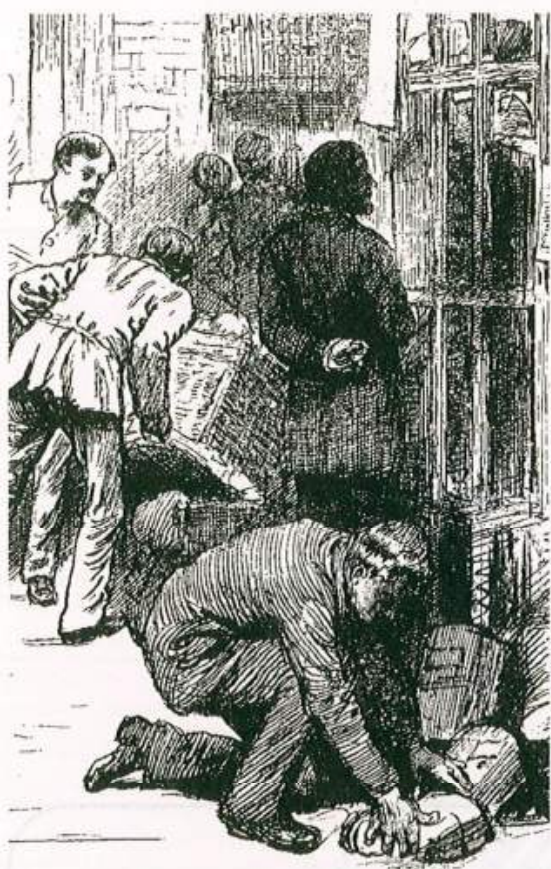

\section{CONTEXTO HISTÓRICO}

Las Fuerzas Armadas, pretendidas como organización nacional, profesional y formalizada, tuvieron un origen paralelo a la formación del Estado Nacional en Colombia.

Las ideas sobre la necesidad de un Ejército Nacional, luego de la desaparición del ejército de independencia, encontraron en Rafael Núñez su más claro exponente. Propósito de la "Regeneración", impulsada por él y por Miguel Antonio Caro a finales del siglo XIX, fue la construcción de un Ejército profesional con oficiales forjados en la academia que, al lado de una Policía Nacional, actuase como base armada constitucional y legitima de las decisiones del Estado centralizado.

Distinto es que, en la práctica, el propósito no correspondiera con la realidad. La confrontación politica y su más cotidiana expresión, las guerras civiles, dificultaron el objetivo. La labor de la Academia Militar bajo la dirección del Coronel norteamericano Henrique Lemly fracasó con la guerra de 1895. La Misión francesa contratada en 1897 fue sacrificada por José Manuel Marroquín, quien decidió cerrar la Escuela Militar y reducir el pie de fuerza ${ }^{1}$. Restaurada por Manuel Antonio Sanclemente en el Batallón Politécnico, la Academia se suspendió definitivamente con el inicio de la Guerra de los Mil Días.

A comienzos del siglo $\mathrm{XX}$, mientras la Policía se debatía en su disolución, el Ejército no era más que un cuerpo amorfo, politizado y diseminado en frágiles divisiones a lo largo y ancho del territorio nacional, sin centralización efectiva, sin coherencia disciplinaria, sin formación táctica y sin grado de profesionalidad alguno. La tarea estaba por hacerse.

La búsqueda de la estabilidad interna, de la centralización y modernización del Estado, concernió con urgencia e impetu al gobierno de Rafael Reyes (1905-1909). Consciente del carácter desarticulado de la sociedad y de la imposibilidad de que ésta lograra por si misma la "construcción del orden", Reyes comprendió que los cambios deseados y operados en las estructuras estatales exigian modificaciones paralelas y correlativas en sus fundamentos legítimos armados. La profesionalización militar se consideró, entonces, base y garantía de la soberanía nacional, de la estabilidad politica interna y del orden social mismo. Era una necesidad vital: las Fuerzas Armadas con carácter nacional entraron a reforzar la tendencia unificadora de la sociedad, organizadora y centralista de la administración civil, y a calmar las preocupaciones generales con respecto a los peligros en la frontera.

Para la élite civil gobernante no dejaba de ser alarmante el hecho que, en Panamá, el contingente militar colombiano se hubiese pasado al lado de los insurrectos separatistas en 1903. Así mismo, las constantes denuncias y el conocimiento directo que el presidente Reyes poseia sobre las crueldades de la Casa Arana y la presencia peruana en el sur del país, conducian a la misma conclusión sobre la necesidad de

1 Con respecto a la Misión francesa, véase: Coronel José M. Forero. "Instrucción militar". En, Boletín Militar de Colombia, Serie VI, Tomo I, Número 1, Bogotá, enero de 1905. un Ejército Nacional. En lo interno, a su vez, el objetivo subyacente a largo o mediano plazo era un ejército profesional y una policia nacional que, alejados de las pugnas partidistas, velaran por la unidad y la seguridad del país entero. La Guerra de los Mil Días se mostró como un fantasma desarticulador ante los ojos de un sistema que anhelaba su unidad e inserción económica en el mundo del capitalismo y del comercio internacional, bajo la aurora rentable de la creciente exportación cafetera.

En ese orden de ideas, la meta de un ejército profesional destinado a la defensa de la soberania y al control interno del orden se convirtió en objetivo inaplazable para Rafael Reyes. En los primeros años de su mandato, Reyes propuso una Reforma Militar, desmontó el voluminoso y politizado ejército heredado de las guerras civiles, procuró recuperar el monopolio del Estado sobre las armas, cambió la distribución orgánica y administrativa del ejército, y dedicó parte de éste a las obras públicas con el objeto de justificar su presupuesto y acercarlo a la nación.

Sin embargo, la decisión más importante de Reyes apuntó a la creación de la Escuela de Cadetes en 1907. Con ella, el gobierno civil aspiraba a reformar la institución armada. Tras ese objetivo, fue también determinante el concepto de Rafael Uribe Uribe. Lider de los liberales radicales del siglo XIX. Uribe visitó a Ecuador como ministro plenipotenciario de Reyes y encontró, bajo el gobierno liberal de Eloy Alfaro, una importante experiencia de profesionalización en el ejército, gracias a la contratación de una Misión Chilena. Luego, con la oportunidad de conocer y admirar en directo la formación que los alemanes impartian en Chile, terminó recomendando lo propio al presidente Reyes ${ }^{2}$.

2 Consúltese, al respecto, Archivo General de la Nación, Bogotá, Sección Academia Colombiana de Historia, Fondo Rafael Uribe Uribe, Rollo 6 / Cajas 14-16. Igualmente, Rafael Uribe Uribe. Por la América del Sur, Bogotá, Imprenta Eléctrica, 1908. 
Al lado de Uribe Uribe, en la delegación diplomática de Colombia radicada en Chile, su secretario Samuel Ramírez Arbeláez trabajó con paciencia para materializar la propuesta. Ramírez era abogado y había ocupado las subsecretarias de los Ministerios de Instrucción Pública y de Gobierno. Con esa experticia adelantó las gestiones necesarias para llevar a buen término la contratación de la Misión Chilena y elaboró las bases del contrato. El compromiso de la Misión Chilena se estipuló en "organizar y administrar" la Escuela Militar en Colombia, dirigir en ella la instrucción práctica y teórica", realizar cursos especiales y de aplicación para jefes, oficiales y suboficiales del Ejército, y corregir los reglamentos de instrucción, régimen interno, alto comando, dirección superior, servicio y estado mayor, entre otros.

El 30 de octubre de 1906, Ramírez comunicó a Uribe que había recibido la orden presidencial de firmar contrato con un capitán de infantería, un teniente de artilleria y un teniente de marina, quienes deberian estar en Colombia en enero de 1907 para iniciar sus labores. El presupuesto asignado para ello fue de cinco mil dólares que se situaban en el consulado de Nueva York en Chile $^{3}$.

\section{LAS MISIONES}

La escogencia de los chilenos como instructores del nuevo Ejército Nacional en Colombia no se sometió al azar. Rafael Reyes vislumbraba las dificultades que habrian de presentarse en la discusión de límites con el Perú; preveía, además, la posibilidad de un conflicto para el cual estimaba importante el apoyo de Ecuador y Chile, y juzgaba necesario prepararse militarmente para impedir los atropellos que el vecino Perú infringía contra la soberania colombiana.

3 Completa información al respecto se encuentra en el Archivo Nacional de la Administración Central, Santiago de Chile. Fondo Ministerio de Relaciones Exteriores, Volumen 1039 y 1249. Antigua nomenclatura 1178 .
Reyes y Uribe conocian de cerca los problemas fronterizos en el sur de Colombia. El primero vivió, en su calidad de empresario cauchero y navegante por el río Putumayo, la perspectiva "usurpadora" y "temible" de los peruanos. El segundo se ocupó de denunciar los múltiples sucesos que implicaban a la empresa peruana "Casa Arana", "en contra del trabajo, la vida y las propiedades de ciudadanos colombianos", así como las violaciones y procedimientos arbitrarios en que incurrian a diario los invasores peruanos en territorio ajeno ${ }^{4}$. Para Reyes y Uribe, Perú era un enemigo potencial y de cuidado; en cambio Chile, enemigo declarado del Perú, era por consiguiente un aliado de Colombia.

Las Misiones Militares chilenas estuvieron conformadas, en su orden, por los siguientes oficiales:

La Primera fue integrada por los Capitanes Arturo Ahumada y Diego Guillén, de acuerdo con la selección realizada por el General Emil Körner, Inspector General del Ejército en Chile, quien la propuso al Congreso de ese país por intermedio del Ministro de Guerra José Francisco Fabres, con la aprobación del presidente Pedro Montt. La ley 8694, fechada el 7 de enero de 1907, oficializó la autorización del gobierno chileno para que sus oficiales prestaran servicio en Colombia, "conservando sus empleos y antigüedades". Con esta Misión se contrató, igualmente, al Teniente Primero Alberto Asmussen para asumir la dirección de la Escuela Naval, comandar un buque escuela y dirigir las obras de defensa en las costas colombianas ${ }^{5}$.

Los capitanes Arturo Ahumada Bascuñán y Diego Guillén Santana, ingresaron muy jóvenes a la Escuela Militar de su país y fueron enviados a Alemania para perfeccionar sus conocimientos milita-

4 Véase Rafael Uribe Uribe. "Colombia en el Caquetá y la invasión peruana" y "Victimas de la Casa Arana". En, Por la América del Sur. Tomo II, op. cit., pp. 397 a 413.

5 Véase Boletín Militar de Colombia. Bogotá, Imprenta Eléctrica, 1907. Serie VII, Tomo II, pp. 99-100.

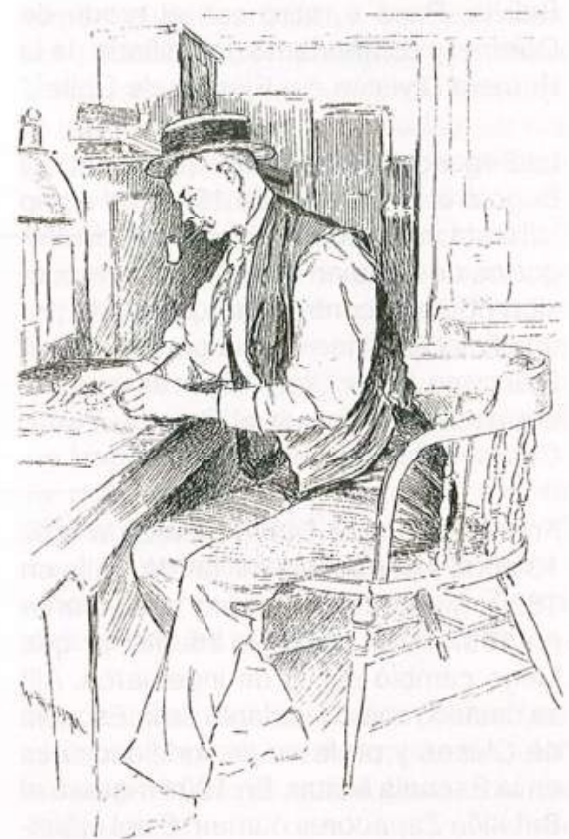

res. Ahumada inició su carrera militar a la edad de 15 años, en 1888. Participó en la Guerra Civil de 1891 y obtuvo el grado de subteniente de infantería un año después. Fue instructor en la Escuela Militar y sirvió como agregado en el Regimiento de Infantería No. 69 del ejército alemán, desde julio de 1902 hasta finales de 1904. Tenia 34 años al momento de llegar a Colombia ${ }^{6}$.

Diego Guillén ingresó de 19 años a la Escuela Militar chilena, en 1895. Se convirtió en instructor de artillería y se graduó como oficial de Estado Mayor en 1906. Regresó como comandante de la Compañía de Cadetes y fue destacado como el mejor capitán del ejército chileno a principios de siglo. Guillén se distinguió como oficial de artilleria y fue agregado militar ante el gobierno de

6 Al regresar a Chile, Arturo Ahumada fue profesor de la Academia de Guerra y nuevamente adicto militar a la Legación de Chile en Alemania entre 1914 y 1917, en plena Guerra Mundial. Pasó a Bolivia entre 1919 y 1920 y fue ascendido a General de Brigada en 1925. Su retiro se le concedió dos años después bajo el título de General de División. Archivo General del Ejército de Chile (en adelante AGECH). Hoja Biográfica del General Arturo Ahumada Bascuñán. 
Bolivia. Pasó a retiro con el grado de Coronel y comandante de artillería de la Primera División del Ejército de Chile ${ }^{7}$.

La Segunda Misión Militar chilena llegó a Bogotá el $1^{\circ}$. de abril de 1909. Tal como lo había solicitado el Encargado de $\mathrm{Ne}$ gocios de Chile en Bogotá, en esta ocasión no se encontraba encabezada por un oficial subalterno sino por un Mayor, Francisco Javier Diaz Valderrama, quien era acompañado por el Capitán Pedro Charpin Vidal, próximo a ascender ${ }^{8}$.

Francisco Javier Diaz ingresó de sólo 13 años a la Escuela Militar de Chile en 1890, graduándose como subteniente en 1892 en el arma de infantería, que luego cambió por la de ingenieros. Allí se destacó como ayudante de la Escuela de Clases y profesor de fortificaciones en la Escuela Militar. En 1901 ingresó al Batallón Zapadores número 5 del ejército alemán, en donde sirvió como adjunto del Estado Mayor de la VI División de Brandeburgo. De Alemania pasó al Estado Mayor General de Suiza en 1904 y de alli regresó a Chile para trasladarse a Colombia, a la edad de 31 años.

Pedro Charpin ingresó a los 17 años a la Escuela Militar de Chile, graduándose como alférez de artillería en 1895. Pasó a la Academia de Guerra en 1900 y fue enviado con el grado de capitán, en 1904, al Regimiento número 10 de Hannover, en el Ejército alemán. En 1905 pasó al Estado Mayor de la V División de Frankfurt hasta 1906, cuando regresó a Chile como miembro del Estado Mayor General del Ejército. Era profesor de topografia en la Escuela Militar, cuando recibió el permiso para formar parte de la Misión, a la edad de 32 años $^{9}$.

La Segunda Misión Chilena abandonó el pais en 1911 y fue sucedida por los oficiales Washington Montero, Pedro Vignola y Manuel Aguirre.

7 AGECH. Hoja Biográfica del Coronel Diego Guillén Santana.

8 ANAC. FMRE. Volumen 1249

9 AGECH. Hoja Biográfica de Pedro Charpin Vidal.
Montero ingresó a la Escuela Militar en septiembre de 1895 y se graduó como alférez de caballeria un año más tarde. Fue destinado a la Escuela de Clases en el escalafón de infantería y enviado a Berlin en 1901. A su regreso, en 1903 , obtuvo el grado de capitán y pasó a la Academia de Guerra, donde ascendió a mayor, poco antes de trasladarse a Colombia, en $1912^{10}$

Pedro Vignola ingresó a la Escuela Militar en 1899 y obtuvo el grado como alférez de artillería en 1900. Se desempeñó en diferentes unidades del arma y pasó a servir, en 1908, en la Escuela de Suboficiales. Alli obtuvo el ascenso a capitán, hasta que fue enviado a Colombia en $1912^{11}$.

Manuel Aguirre se graduó en el arma de infantería en 1902 pero cambió al arma de ingenieros, con la cual adquirió el grado de instructor en la Escuela Militar Chilena. Más adelante pasó al Estado Mayor General, donde ascendió a capitán y fue autorizado para trasladarse a Colombia en $1912^{12}$

El último intento por sacar adelante la Reforma Militar en Colombia quedó en manos de un sólo hombre: Carlos Sáez, el oficial chileno que reemplazó a Vignola, y a quien el gobierno nacional solicitó prolongar su comisión y permanecer en Colombia hasta 1916. Sáez empezó su carrera militar como conscripto en una unidad de artillería; se vinculó a la Escuela de Clases del Ejército chileno en enero de 1897 y obtuvo el primer puesto de su promoción para ganar el derecho a ser enviado a la Escuela Militar, en donde se graduó como alférez de artillería. Ingresó a la Escuela de ingenieros militares y cursó estudios en la Academia de Guerra. En 1908 fue enviado al Ducado de Hesse en Alemania y de alli pasó a formar parte de la Comisión Krupp, bajo las órdenes del General Körner,

10 AGECH. Hoja biográfica y de antecedentes militares de Washington Montero.

11 AGECH. Hoja biográfica y de antecedentes militares de Pedro Vignola.

$12 \mathrm{AGECH}$. Hoja biográfica y de antecedentes militares de Manuel Aguirre.

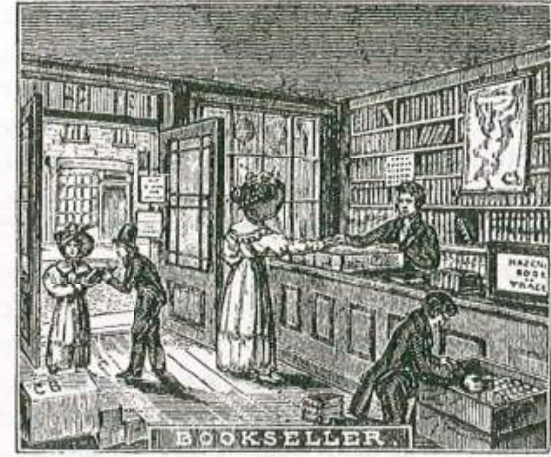

quien habia retornado a su pais. Cursó estudios en Francia, Austria e Italia y regresó a Chile, en 1912, donde publicó su primera obra: "Apuntes sobre el tiro por tiempo", poco antes de trasladarse a Colombia ${ }^{13}$.

\section{LA INFLUENCIA CHILENA.}

\subsection{Defensa de la carrera militar}

En Colombia, como en gruesa parte de América Latina, el ascendiente recibido por el ejército de las misiones militares extranjeras fue considerable e importante. Pero no sólo en términos de capacitación castrense; en cierta medida, los extranjeros fueron también agentes de un proceso de formación conceptual, de transmisión de su mentalidad ${ }^{14}$, e inculcación de patrones inherentes a la profesión militar.

Probablemente, la influencia más importante que los alemanes transfirieron al ejército chileno, y este a su vez al colombiano, residió en la conformación de un "ethos" profesional de la oficialidad que, además de la preparación para la guerra, establecia el honor sacrificial y el amor privilegiado hacia el concepto "Patria".

13 AGECH. Hoja biográfica y de antecedentes militares de Carlos Sáez.

14 Véase, Frederick Nunn. "An overview of the european military missions to Latin America", en: Brian Loveman y Thomas Davies Jr. (Eds) The politics of antipolitics. Nebraska, Nebraska university press, 1978. 
Los oficiales alemanes no sólo eran portadores de conocimientos militares. En ellos se conjugaba el ideal de jefe heroico, proveniente de pensadores como Fichte y Hegel, y la ideología feudal de los junker, cuyo ideal lo constituía el oficial de ejército. El mito racial y el pangermanismo llegarían a su comprensión a través de Duhring y de Wagner; la visión de Estado a través de Schilling y del mismo Hegel.

La formación ideológica era un fiel reflejo de la ideologia dominante en Alemania, de orientación nacionalista y espiritu expansionista. Por ese motivo, la formación del oficial consultaba el respeto al poder, la deificación del Estado y de las clases en que se personificaba la defensa de la propiedad privada y del orden establecido. Como características personales, la puntualidad, la limpieza, la honradez y la abstinencia, hasta convertir la disciplina en "carne y sangre del soldado"15. Aspectos básicos en la formación militar prusiana que serán descritos por Ernst Jünger como "moral de renunciación" y "abolición de la personalidad en provecho del ideal social y moral de Alemania en nuestra madre, la guerra"16.

Los chilenos conservaron de manera fiel la idea del "ejército nacional" como escenario tangible de la unidad y coherencia entre "el estado político" y "el estado militar". Según Francisco Javier Díaz, para que tal unidad fuera posible debía existir perfecto equilibrio entre el orden, la libertad y la disciplina cívica, de manera que esta última fungiera como impulsora en la constitución del ejército nacional. Debía existir, además, armonía entre el ejército nacional y los intereses económicos del país, y entre los oficiales

15 Emil Körner. Die historische entwicklung der chilenischen wehrkraft. Berlin, 1910 La traducción al español y comentarios sobre la obra pueden observarse en: Patricio Quiroga y Carlos Maldonado. El prusianismo en las Fuerzas Armadas chilenas. Santiago, Ediciones Documentas, 1988.

16 Ernst Junger. Jardins et routes: pages de journal. Paris, Plon et nourrit, 1942. y su espiritu institucional como apego al Estado ${ }^{17}$.

En las misiones australes prevaleció la construcción conceptual de aquello que podemos denominar la virtus militar. Se trata de ideas y conceptos referidos a la conducta militar y su existencia misma, que intentan reivindicar el sentido mesiánico que los uniformados construyen con sus armas en torno a la pervivencia del Estado y la Nación. La deontologia se estructura para que los oficiales desarrollen un ethos adecuado y pertinente en términos de virtud, y sigan comportamientos correspondientes a su exclusiva profesionalidad. La vocación aparece como sentido místico, ético y casi sacerdotal, provisto de significados y valores distintivos frente al resto de la población.

Sin embargo, la influencia de las misiones chilenas en Colombia fue matizada por el control que el conservatismo reinante y en general las élites civiles sostuvieron sobre la Escuela Militar. Ninguna de las misiones alcanzó el preponderante papel que obtuvo Körner en el ejército chileno. Aunque la altura intelectual de la segunda misión austral le permitió sortear los embates y la censura de la dirección gubernamental, ni ella ni mucho menos la siguiente pudo garantizar el predominio de sus criterios en la administración burocrática del ejército y en la formación de la oficialidad.

Por el contrario, los ideales y propósitos de las misiones, sus códigos y discursos se vieron trascendidos por las prácticas sociales y partidistas. Contra los intentos de formación técnica confabularon los constantes cambios de acantonamiento, los llamados a calificar servicios, la selección partidista de los aspirantes a la Escuela, el obligado retiro de jóvenes que apenas se introducian en la carrera militar y el bajo presupuesto asignado a los asuntos de la guerra. Al sistema de ascensos por méritos, que llevaría al oficial a confiar en su propio esfuerzo por encima de las identificaciones y

17 Francisco Javier Diaz. A propósito de nuestra politica militar, una serie de articulos publicados en "El Mercurio". Santiago, 1938. expectativas partidistas, se opusieron las presiones de la dirigencia política enclaustrada en lo más tradicional de la clientela. Obstáculos creados por los grandes propietarios, por los gamonales y los curas, impidieron desde sus localidades la vigencia de un servicio militar obligatorio legislado a medias e inaplicable en la práctica concreta. El reclutamiento continuó ejercitándose sobre la población paupérrima de las zonas más partidizadas o como sistema local de vindicta; la prohibición del voto militar quedó aplazada y la misma Escuela Militar perdió su trascendencia. Al final de su gobierno y acosado por la oposición, el propio presidente Rafael Reyes defeccionó en sus ideas de reforma.

No obstante, no todo fue en vano. Los chilenos dejaron, sin duda, una singular simiente en sus alumnos. La derrota de Balmaceda y del Estado centralista en Chile dejó en los militares de ese pais una amarga sensación de frustración. Frente a ella, el militar pretendió convertirse en la conciencia moralizadora del Estado y en garantía de la gobernabilidad. Este fue el marco bajo el cual la Segunda Misión Chilena, recién llegada a Colombia, decidió intervenir para evitar un golpe contra la posesión del General Ramón González Valencia como presidente de la República en 1909. De alguna manera, los chilenos se acercaban más a las instituciones y encontraban mejores aliados para el proceso de profesionalización en la facción conservadora de González y sus cofrades liberales. Eran éstos últimos quienes pedían un ejército alejado de la política y de los caudillos, como lo anhelaban los australes en su propia Patria.

En esta dirección, la concepción de los chilenos tuvo su expresión más importante en la construcción de una ética de servicio que tenía como fin despojar al militar de las identidades partidistas para construir lealtades frente al Estado y sus instituciones. El Ejército Nacional sólo podía usar como bandera el pabellón tricolor. Los oficiales tenían que ser, simplemente, "soldados de la Patria". El mérito personal en el servicio, basado en el cumplimiento irrestricto de esta condición y de las obligaciones propias de cada rango, se convirtió en reiterada 
solicitud de los militares para mantener el respeto a su carrera y el carácter legítimo de los ascensos.

El oficial tenia que formarse a lo largo de su carrera y no en los directorios políticos o en el tráfico de influencias. La intromisión de estos últimos factores apuntaba al corazón mismo de la Escuela, a su razón de ser y de existencia. La profesionalización era la única manera de afianzar el espíritu militar y de asegurar la rectitud de los oficiales; la intrusión de la política partidista en su carrera era la forma más efectiva de obtener su desmoralización.

El propósito de los chilenos, sin embargo, no fue atendido con el rigor que se exigía. Los altos funcionarios del Estado no estuvieron nunca dispuestos a abandonar la influencia partidista y clientelar sobre la fuerza pública. De cierta manera, la visión de "Patria" que impulsaban los chilenos no encontraba expresión ni apego en la precaria visión de nación unificada que ostentaban los políticos. Por el contrario, el Ejército resultaba un mecanismo apto para inscribirlo en una concepción premoderna de la democracia, en donde las instituciones del Estado formaban parte de la distribución y correlación de fuerzas entre los partidos. Para hacerlo, el Ministerio recordaba la Ley 28 de 1871, por la cual se declaró que los grados militares eran empleos susceptibles de proveerse con individuos de cualquier clase y categoria, sin importar sus conocimientos militares.

Al comentar el desarrollo de la Reforma Militar y la labor de la Misión chilena a partir de su intervención para defender el gobierno de González Valencia, la revista "Cultura", dirigida por Luis López de Mesa y en la cual participaba Tomás Rueda Vargas, presentó una correcta síntesis del problema:

"Las misiones chilenas impusieron en la oficialidad colombiana el criterio de la defensa constitucional con la relativa facilidad con que se cumplen en Colombia las medidas legalistas y se acepta el criterio de justicia; más no sin que tuvieran que vigilar con decisión de centinela avanzada, tentativas desdorosas de la añeja política. Quedaba el país libre de militarismo partidarista, libre de las conjuraciones de cuartel, libre del enganche forzado de labriegos. Pero venian sobre el gobierno dos terribles obligaciones: la de respetar el escalafón en una justicia de ascensos rigurosamente preparados, y la de no atender a las condiciones sociales de los conscriptos impuestos por la ley. $E$ fracaso no se hizo esperar entonces. Los graves compromisos del pasado y el hálito fatídico de la saña de otros tiempos forzaron la puerta sagrada de los ascensos con intromisiones que desconcertaron a la oficialidad que habia empeñado su vida a esa carrera; y un retraimiento preñado de sombras indicó la puerta de salida a supuestos adversarios de un orden que creiamos caduco ya"18.

Por supuesto, la conciencia contra la manipulación burocrática de los políticos se hizo evidente en gruesa parte de los oficiales más jóvenes. Aunque su disgusto no alcanzó el nivel de la protesta de los tenientes en Brasil $^{19}$, debido a la fortaleza de la élite civil y al poder de los oficiales superiores congraciados con el cuerpo administrativo del Estado, si quedó expresa constancia de la fuerte indignación en múltiples retiros y en escritos que vieron la luz pública.

\subsection{Simientes para la construcción de una "mentalidad militar"}

En materia concerniente a la mentalidad militar, que Samuel Huntington define en torno a su capacidad, atributos y actitu$\operatorname{des}^{20}$, existen limitaciones para rastrear las representaciones de los militares en el inicio de su profesionalización. Una fuente importante, sus memorias y auto-

18 Revista Cultura. Editorial. Vol. 1, No. 4. Bogotá: mayo de 1915.

19 El "tenentismo" en Brasil se expresó en movimientos como la Revolución del Fuerte de Copacabana (1922), la Revolucion Paulista, la Comuna de Manaos y la Columna de Luis Carlos Prestes.

20 Samuel Huntington. The soldier and the state: the teory and politics of civilmilitary relations, Cambridge, Harvard University Press, 1957. biografias, es prácticamente inexistente en Colombia para la época en estudio. Se adolece, en este sentido, de una obra como la escrita por el General Carlos Sáez para la historia militar chilena ${ }^{21}$. Las reflexiones intimas de los uniformados, la memoria matizada por el tiempo que permite el análisis sobre modelos conceptuales que no suelen aparecer en otras fuentes, brillan por su ausencia.

No obstante, algunas huellas pueden encontrarse en los escritos que los oficiales entregaban a las revistas militares. En el Memorial del Estado Mayor, por ejemplo, no es difícil hallar la impronta del magisterio chileno. En 1922, uno de sus alumnos insistia:

\begin{abstract}
"Aquel sabio principio que tantas veces oímos de nuestros maestros, los distinguidos oficiales chilenos que nos iniciaron en las lides de la guerra, de que 'todo comandante tiene una doble misión que desarrollar ante su tropa: ser su instructor y ser su educador', tiene hoy dia más que nunca una fuerza incontrastable..."22.
\end{abstract}

Los conceptos individuales del honor militar, de la probidad cívica del patriotismo, el deber y la obediencia, propios de la virtus militar que los chilenos enseñaron, aparecen una y otra vez en los postulados de los militares colombianos:

"El honor y el patriotismo inspiran los más grandes y nobles sacrificios, como que son caridad y amor, y el amor a la Patria no admite vacilaciones. El espiritu de sacrificio y la voluntad de vencer basada en la esperanza, aseguran el éxito; la disciplina y la solidaridad garantizan la acción de los superiores y, en una palabra, la fuerza de la educación moral adquirida en la paz, asegura la eficacia y la unidad de acción en la guerra"23.

21 Carlos Sáez. Recuerdos de un soldado, Santiago de Chile, Ercilla, 1934.

22 Mayor Marco A. Pardo. “De la educación moral del soldado". En, Memorial del Estado Mayor, Año XII, Vol. 15, Bogotá, Talleres Gráficos del Ejército, 1922, p. 21-22.

23 Ibidem. 


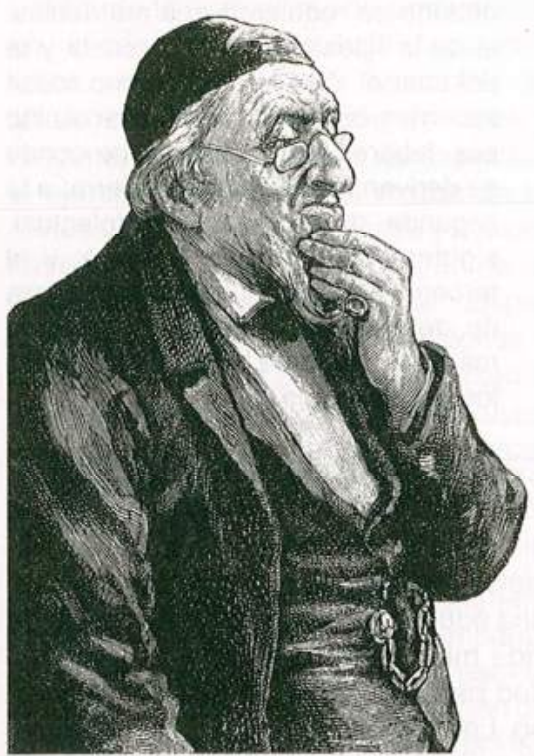

"La educación del soldado será de dos tipos: física y moral. La primera comprende el desarrollo corporal, la destreza para la guerra, el hábil manejo y uso de las armas. La segunda comprende el desarrollo del carácter, la obediencia, la fidelidad, la responsabilidad, el ánimo y el valor"24.

La idea de servicio público y de sacrificio por la Patria, aparte de la lealtad y la obediencia, son virtudes que construyen el discurso de los militares como modelo de auto-representación frente a la sociedad. Para los chilenos, la misión del oficial se centraba en despertar sobre los soldados el amor a la Patria y a su historia:

"Instruirlos en sus deberes civicos i militares i hablarles con frases sencillas, de una manera tal, que logrando atraer e interesar a esos sencillos corazones, los impulse por el camino del bien i por el estricto cumplimiento de sus deberes, tanto cívicos como militares, arrancándolos a esa vida de malos ejemplos, que es jeneralmente la que sigue nuestro roto(sic)"25.

24 Capitán Luis Acevedo. Memorial del Estado Mayor. Año III, Cuaderno 1, marzo 1 de 1913. Bogotá: Talleres Gráficos del Ejército.

25 Memorial del Ejército de Chile, Cuaderno V, Año XI. Santiago: Talleres del Estado Mayor, 1916.
Los discípulos colombianos reprodujeron una y otra vez la orientación convertida en piedra angular para su propio "ethos":

"Es necesaria una educación moral (para el soldado) que robustezca su carácter y su amor propio, que purifique y eleve su dignidad y que haga arraigar en su corazón la convicción de que se debe todo entero a la Patria"26.

"La defensa de la Patria es una obligación tan sagrada como lo es el defender a la propia madre contra cualquier peligro, ultraje o insulto"27.

Una nueva liturgia militar exaltó, entonces, los motivos patrióticos de la guerra. Según lo confesaron tiempa después, esta liturgia significó para los oficiales en formación un nuevo sentido en la carrera de las armas. Se trataba de jóvenes que, en su infancia, no pudieron siquiera entonar un himno nacional porque no existía, que pasaron por la escuela primaria dedicados a la historia de Roma o de Grecia por que la historia de Colombia no contaba con un manual que permitiera a los maestros su enseñanza, o porque ésta era un cúmulo de guerras civiles y enfrentamientos partidistas fratricidas. Ahora, el concepto "Patria" reeditaba en sus corazones una gesta militar noble y heroica que se encontraba próxima a cumplir un siglo.

Esa nueva liturgia descansaba en la supremacia de los valores militares por sobre la identidad partidista y por sobre la impúdica concupiscencia de las acciones civiles. La satisfacción del oficial, lleno de espiritu militar, estaba en su trabajo por el ideal elevado, de trascendencia, de verdadera importancia, por el bien de la Patria. La pugna partidista, con sus mundanas desvergüenzas, correspondia a los civiles.

26 Teniente José A. Papa. "La educación moral del soldado". En, Memorial del Estado Mayor. Año XI. Vol. 14. Bogotá: Talleres Gráficos del Ejército, 1921. p. 423.

27 Mayor Marco A. Pardo. Memorial del Estado Mayor. Op. cit.
El valor del soldado en la guerra dependia, entonces, de la instrucción y de la "educación moral" que en torno al principio "Patria" recibiera en tiempos de paz. Una adaptación chilena a la doctrina de Clausewitz, para quien la ciencia militar comprende la preparación para la guerra durante la paz y la conducción táctica y estratégica de las tropas durante la guerra. Si la tropa conocía sus deberes para con la Patria, la alta misión que le incumbe como defensora de la soberania y de la integridad nacional por encima de la política y con sentido patriótico de abnegación, soportaria con seguridad las privaciones y peligros de la guerra.

"La fuerza moral de los ejércitos está basada en la disciplina, llamada con razón el alma de la institución militar. que en resumen comprende: confianza en Dios, amor a la Patria y a la gloria, valor, fidelidad al deber, abnegación, obediencia, cumplimiento de las órdenes y reglamentos con inteligencia y conforme al espiritu de ellos"28.

Prepararse para la guerra exigia, por consiguiente, la profesionalización del ejército para responder a las necesidades de la Patria. Los peligros que recaen sobre ella subordinan todas las necesidades a las de la guerra. La Patria es la madre máxima; aquella ante la cual el sacrificio no puede tener límites, aquella ante la cual debe ofrecerse la vida para salvarla del peligro. Los textos de una prueba que la Misión chilena hizo a sus alumnos y que se conservan en archivo, son una muestra de las lecciones ofrecidas en el aula:

“¿Cuál es el primer deber del soldado? La fidelidad inquebrantable prometida en juramento a la bandera y esta es la insignia con que la Patria representa su soberanía. ¿Qué es la Patria? Es la tierra donde se nace, la que tiene más derecho que nadie a los sacrificios y hasta a la vida de sus hijos. El soldado es un ciudadano que la Patria mantiene armado para que la defienda. ¿Cómo debe portarse el soldado en la

28 Capitán C. Rojas. "Necesidad de un cuerpo de suboficiales instructores". En, Memorial del Estado Mayor. Año III. Cuaderno 1. Bogotá: Talleres del Estado Mayor, 1913. p. 286 
guerra? Debe tener ánimo en todas las obligaciones del servicio, valor en el combate, obediencia a sus superiores y observar una conducta intachable en el servicio y fuera de él. Está obligado a emplear todos sus conocimientos sacrificando su vida con el objeto de alejar los peligros que amenazan a la Patria"29.

\subsection{Bases para la normalización profesional}

Una de las condiciones necesarias para el surgimiento de la profesión militar es la normalización de los problemas y sus soluciones en el campo de actuación. La normalización presupone perspectiva y prospectiva, organización, planeación y previsión; establece los parámetros y demarcaciones dentro de los cuales se circunscribe y se mueve la profesión. La importancia de la normalización en el proceso de profesionalización radica en que la profesión sólo puede establecer sus márgenes de competencia y de poder cuando ella se halla plenamente establecida. Sólo cuando se ha alcanzado la exigencia de normalizar los problemas y sus soluciones, es posible organizar la formación que garantiza la capacitación profesional sobre la que se basa el monopolio de la profesión. La normalización impulsa, en ese sentido, el más primario pero fundamental "espiritu de cuerpo"30.

En las profesiones tradicionales, como la militar, la normalización acentúa la prestación del servicio, la ética profesional y la integridad. Por esa razón se exige a los oficiales un comportamiento intachable dentro y fuera del cuartel, un "estilo de vida correcto", ejemplo para sus subalternos y probo frente a la sociedad. La vida del militar rompe con la vida del civil. Al ingresar a la Escuela Militar, el joven alférez debe descargar su carácter civil y asumir la vida militar

29

Escuela Militar de Cadetes, Libro de Archivo 1911, Museo de la Escuela.

30

Véase Gerke Teitler. "Theoretical aspects". En, The genesis of the professional officers corps, Beverly Hills, Sage publications, 1977. con todo lo que ello implica. La nueva fase de su vida es superior a la anterior. La hombria y el honor, al lado de los valores más tradicionales de la sociedad, aparecen como justificación y razón para atreverse a vivir la carrera militar.

EI Ejército "es la reunión de soldados listos para la defensa de la Patria", enseñan los chilenos ${ }^{31}$. Corresponde al oficial la construcción de ese ejército; forjarlo en la moral con su propio ejemplo, conducirlo en la guerra con la disposición al sacrificio. El cuerpo de oficiales constituye ei cuadro permanente encargado de preparar a la nación para la guerra.

"La nación necesita un ejército capaz de defender sus instituciones y de que el pais se prepare militarmente, es decir, que los ciudadanos adquieran en los cuarteles los conocimientos necesarios para que representen en conjunto la fuerza de defensa nacional y mantengan el concepto de respetabilidad patria ante el mundo entero"32.

Los oficiales, portadores de semejante misión, responsables de tan magna tarea, son hombres de un carácter especial, mesías y héroes que escapan al común de los mortales. En tanto alma del ejército, los oficiales deben personificar las virtudes y cualidades que caracterizan a ese ejército en el terreno de las distinciones, de los honores, de las dignidades, pero también de la disciplina y la obediencia. Los oficiales son apóstoles de una fuerza que representa la disciplina y la conciencia, la obediencia digna y sentida, "todo lo cual riñe con las modalidades de nuestro pueblo"33. Pero, precisamente por ello, el oficial es un maestro:

"La formación del ciudadano está al cuidado de tres maestros: el cura, el maestro de escuela y el oficial. Por consiguiente, para llegar a ser ciu-

31 Escuela Militar de Cadetes. Libro de Archivo 1911. Museo de la Escuela.

32 Mayor Marco A. Pardo. Memorial del Estado Mayor. Año XI. Vol. 14. Bogotá: Talleres Gráficos del Ejército, 1921.

33 Capitán C. Rojas. "Necesidad de un cuerpo de suboficiales instructores". Op. cit. p. 426 . dadano se requieren tres matrículas: la de la Iglesia, la de la escuela y la del cuartel. A la primera, como todos sabemos, corresponde enseñar al niño sus deberes para con Dios, de donde se derivan los demás en la tierra; a la segunda, darle educación intelectual, siguiendo la ruta del primero; y al tercero, enseñar al joven la manera de defender a la Patria, y además mantener en firme las enseñanzas de los dos primeros" ${ }^{134}$.

Exigencia de la normalización, implantada con rigor por los chilenos, fue el aislamiento de los aprendices de oficiales con respecto a la influencia civil, una educación estricta sobre el estilo de vida militar y la búsqueda de uniformidad para conservar la unidad de cuerpo. Las Misiones chilenas, por ejemplo, demandaron al gobierno reemplazar la forma de alimentación en los cuarteles. A cargo de las mujeres de los soldados, de las "juanas". Este anacrónico sistema representaba un impedimento total para la profesionalización del ejército.

Así mismo, los chilenos se hicieron célebres por el carácter inflexible e irreflexible de su disciplina y por el extremo cuidado que impusieron a la vida de cuartel. En su concepto, la vida en común, las fatigas y progresos, creaban unidad de cuerpo y de nación. La idea del Estado-guarnición, trasladada de Alemania, elevó la sumisión militar al carácter de virtud y la orden superior al estrado de mandato divino. La "disciplina prusiana" reglamentó la relación entre oficiales y subalternos sobre la base del principio "orden y ejecución inmediata", obediencia y eficacia.

La calificación del oficial, como requisito y medida para el ascenso, fue considerada por los chilenos como pieza fundamental en el proceso de profesionalización. La calificación constituye el exponente del estado de preparación alcanzado por el oficial y que permite, a su vez, inferir el estado de la tropa. Los superiores encuentran en la calificación las caracteristicas del oficial y sus condiciones para un servicio determinado.

34 Mayor Marco A. Pardo. Memorial del Estado Mayor. Op. cit. 
Dentro de la normalización profesional, en sentido más amplio, la Misiones chilenas consagraron parte importante de su actividad a la redacción de leyes y reglamentos que, además de organizar al ejército, delimitaran el marco de la profesión militar, sus funciones y acción. Leyes como la llamada "Militar de la República", "de servicio militar obligatorio", "de sueldos", "retiro, pensiones y montepio", que los chilenos redactaron y presentaron al Congreso, constituyen una muestra de su interés por abarcar todos los aspectos referentes a la profesión del militar.

Los chilenos dejaron también reglamentos de gimnasia, de servicio en campaña, del servicio de guarnición, de tiro para la artilleria, de uniformes, de calificación de oficiales y el orgánico de la Escuela Militar, entre otros. Adelantaron, igualmente, las tareas necesarias para la creación de la Escuela Superior de Guerra y las escuelas de aplicación específica de caballeria, artilleria y suboficiales.

\section{INFLUENCIA EN DOBLE VÍA}

El Ejército colombiano y la estadia misma en nuestro territorio fueron también refractarios para los chilenos. La interacción con los jóvenes oficiales, la relación con los poderes partidistas, del gobierno y del Estado, asi como los múltiples conflictos que vivieron en defensa de sus esquemas y principios, dejaron huellas visibles a lo largo de sus vidas y carreras militares.

Probablemente, la influencia sobre los miembros de las misiones no alcanzó el nivel de aquella que EI Salvador marcó en el General Carlos Ibáñez. Teniente instructor de caballeria, subdirector y director de la Escuela Politécnica Militar de ese país, decidió comprometerse a disgusto de sus superiores y del gobierno chileno en la guerra de 1906 contra Guatemala y se convirtió en héroe reconocido de la Batalla de "El Platanar". Más aún, contrajo matrimonio con una joven de ilustre prosapia, que incluía entre sus parientes a un Vicepresidente y a un Presidente de la República de El Salvador, y consideró a ese país como su "segunda patria".

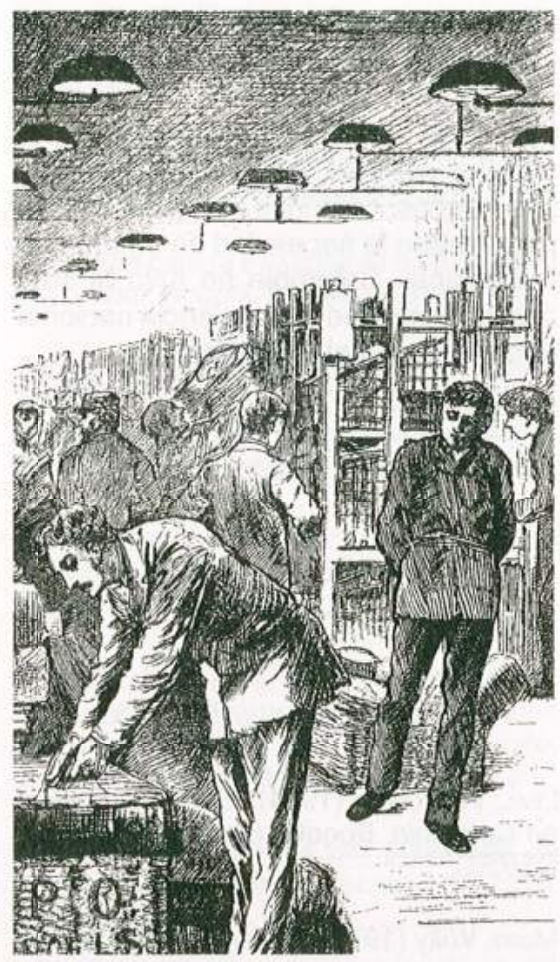

Francisco Javier Diaz profesó también profundos afectos hacia Colombia. En forma constante remitió artículos de su autoría para las revistas militares y mantuvo contacto con sus discípulos más apreciados. En 1911, tras lo ocurrido en La Pedrera, impulsó una campaña entre particulares y empresas de la capital, destinada a la recolección de fondos para la compra de armamento. Él mismo dio ejemplo entre los militares y donó parte de su salario para ese objetivo. En 1932, sin la plena complacencia del gobierno chileno, no vaciló en prestar sus servicios para el conflicto con Perú. A pesar de sus ideas, en ese momento simpatizantes del nazismo alemán, guardó respeto frente a las decisiones del poder civil y frente a las concepciones liberales del gobierno. En cierta forma, la influencia de los dirigentes civiles en Colombia pudo haber sido más importante para Díaz, que aquella ejercida por él en Olaya, López Pumarejo, o incluso en su amigo Guillermo Valencia.

La derrota de la Reforma Militar, por otra parte, debió dejar su impronta en los oficiales chilenos. Francisco Javier Díaz y Carlos Saez fueron grandes opositores a la intromisión de la política en los medios castrenses de su país ${ }^{35}$. Ambos se quejaron de la actitud despectiva y denigrante de la élite civil con respecto a los militares y desplegaron sus esfuerzos para una profesionalización acorde con los postulados de sus maestros alemanes. En Chile, como en Colombia, los miembros de las misiones se preocuparon por el sistema de instrucción y la formación de oficiales y suboficiales, por la organización de las unidades y los regimientos, el sistema de reclutamiento, el papel del Estado Mayor General y el sistema de preparación táctico y estratégico de las fuerzas.

La defensa del reclutamiento universal estuvo relacionada con un concepto de Estado-Nación que compartieron las misiones chilenas, y en el cual todos los connacionales tenian la obligación del servicio militar. En ese sentido, buscaron en las leyes un efecto uniformador para esa condición común representada en la nacionalidad y en la Patria que, además, protegía al ejército de las amenazas partidaristas

En Chile, los militares comprobaron igualmente los límites de los recursos materiales disponibles para su progreso y la posición de una clase política que no estaba interesada en próveerles mas allá de lo que el riesgo inmediato aconsejaba y percibía. Al tiempo que algunos alumnos colombianos se quejaban del desdén a que eran sometidos, los maestros chilenos no dudaron en tomar parte de los levantamientos que reivindicaron su condición deliberante. Ahumada, por ejemplo, subrayó la importancia del bienestar social para las fuerzas militares ${ }^{36}$ y Vignola, sin abandonar sus prevenciones para con los civiles, invocó en diversas ocasiones el apego a la constitucionalidad.

35 "La participación activa en política destruye la unidad del cuerpo de oficiales". Francisco J. Díaz. "Artículos sobre la organización militar en Chile", Santiago, Editorial La Cruz Svástica, 1932

36 Arturo Ahumada. El Ejército y la Revolución del 5 de Septiembre de 1924. Santiago, Imprenta La Tracción, 1931. 
La Reforma Militar iniciada por las Misiones Chilenas en nuestro país no atravesó un lecho de rosas. Año tras año, las dificultades se hicieron más presentes. Los opositores aparecieron en el mismo Ejército, entre los viejos generales de las guerras civiles; en sectores importantes del gobierno y el Partido Conservador, convencido de que los chilenos buscaban la liberalización del Ejército; en franjas politizados de la opinión, o incluso en la diplomacia peruana, quien no estimaba con agrado la formación de futuros generales colombianos por oficiales chilenos. A pesar de que diversos hechos ocurridos en la Amazonia subrayaban la necesidad de un Ejército profesional, Colombia no tuvo la suficiente capacidad ni conciencia nacional para sacar avante la Reforma.

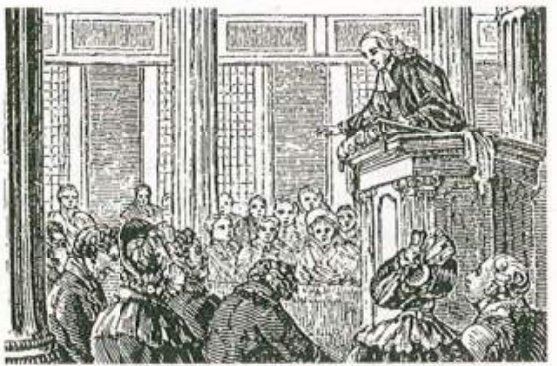

Zambrano, Ramiro. "Siluetas para una Historia”, Revista del Ejército No. 29, Bogotá, suplemento especial, s.f.

en Combia. Botá: Siglo XXI Edto CEREC.

MuRY, Willy (1975). L'armée colombienne. Etude d'une institution militaire dans ses rapports avec la société en transition, 1930-1974. Tesis de Doctorado, Universidad de París, 1975.

PInzon, Patricia (1994). El ejército y las elecciones. Bogotá: Cerec.

BERMUDEZ, Gonzalo 1982). El Poder en Colombia. De la Colonia al Frente $\mathrm{Na}$ cional. Bogotá: Editorial América Latina.

Bonilla, Jaime (1978). Luis Enrique Bonilla. Episodios de la vida civil y militar de Colombia. Bogotá: Canal RamírezAntares.

Escuela Militar de Cadetes General José Maria Córdova (1997) Noventa años de historia. Bogotá: Ejército Nacional.

Helg, Aline. "El desarrollo de la instrucción militar en Colombia en los años 20. Estudio del impacto de una misión militar suiza". En Revista Colombiana de Educación No. Bogotá, Centro de Investigaciones Universidad Pedagógica Nacional. pp.

ICENHOUR, James (1976). The military in Colombia Politics. Dissertation Ph.D., The George Washington University.

Jaramillo, Carlos E. (1989). "Antecedentes de la Guerra de los Mil dias y golpe de estado del 31 de julio de 1900", En Nueva Historia de Colombia, (NHC). Bogotá, Planeta, 1989. Vol. I, Cáp.3. pp. 65-88.
PizarRo, Eduardo (1987-1988). "La profesionalización militar en Colombia", Análisis Político, Bogotá, IEPRI-Universidad Nacional, No. 1, 2 y 3.

Pizarro, Rafael y Orejuela, Liborio (1957). 50 años de la Escuela Militar. Bogotá: Servicio de Imprenta y Comunicaciones de las Fuerzas Armadas de Colombia.

Rodriguez, José Jaime (1993). "El Ejército del siglo XX. De Reyes a López. La reforma militar". En Historia de las Fuerzas Militares de Colombia. Ejército. Bogotá, Planeta, 1993, vol. II, Capítulo 28.

Rueda Vargas, Tomás (1944). El Ejército Nacional. Bogotá: Libreria Colombiana, Camacho Roldán y Cia. Ltda., Ed. Antena.

VAlENCIA T. Álvaro. (comp).(1996). Historia de las Fuerzas Armadas en Colombia. Bogotá: Editorial Planeta. 8 Volúmenes.

\section{DOCUMENTOS Y ARTÍCULOS EN REVISTAS MILITARES}

Acevedo, Luis. Memorial del Estado Mayor, Bogotá, Talleres Gráficos del Ejército, Año III, Cuaderno 1, marzo $1^{\circ}$. de 1913.

Ahumada, Arturo. El Ejército y la Revolución del 5 de Septiembre de 1924. Santiago, Imprenta La Tracción, 1931.

Andrade Anaya, Alberto. "La reforma militar de 1909", in Revista de las Fuerzas Armadas, Bogotá, vol. XXXVIII, No.111 (abril-junio, 1984).

Autor anónimo. "La obra de las Misiones Militares Chilenas en Colombia", Revista Militar del Ejército, Bogotá, vol. 23, No. 218 (agosto, 1930).

Baquero, Elias. Colombia. La Misión Chilena y el Ejército. Bogotá, Imprenta Moderna, 1911.

Borrero, Arturo. (Coronel). Exposición sobre armamentos del Ejército, Bogotá, spi., 1924.

Burbano, Sergio A. Intervención en sesión de la Cámara de Representantes. Bogotá, s.p.i., 8 de agosto de 1916. 
Charpin, Pedro. El Problema del Armamento. Bogotá, s.p.i., 1911.

"El Ejército: su razón de ser", conferencia dictada en agosto de 1909 , s.p.i.

Diaz, Francisco J. El Ejército que Colombia necesita. Bogotá, Imprenta de Juan Casis, 1934.

\section{2.}

La guerra civil de 1891. Santiago,

Conferencias sobre organización militar. Bogotá, Imprenta La Luz. s.f.

----.-A propósito de nuestra política militar: una serie de artículos publicados en "EI Mercurio". Santiago, 1938.

---.. "La participación activa en política destruye la unidad del cuerpo de oficiales", in Artículos sobre la organización militar en Chile. Santiago, Editorial La Cruz Svástica, 1932.

--.. Proyecto de leyes militares presentados al supremo gobierno de Colombia. Bogotá, Imprenta Nacional, 1911.

---. Memorando para la ejecución de los trabajos del Estado Mayor y del Ministerio de Guerra. Bogotá, Imprenta Eléctrica, 1911.

. "Estudio sobre la defensa territorial de Chile", Memorial del Estado Mayor General del Ejército de Chile, julio 15 de 1906.
" "El significado del arma de tren", Memorial del Estado Mayor del Ejército de Colombia, No. 19, año IV, vol. IV, 1914.

Diaz y ChaRpin. Directiva para la instrucción de la Escuela Militar. Bogotá, s.p.i., 1911.

---.. Guía para la Enseñanza de organización militar. Bogotá, Imprenta La Luz, 1911.

Estado Mayor General del Ejército. Historia del Ejército de Chile. Vol. VII. "Reorganización del Ejército y la influencia alemana (1885-1914)". Santiago, 1982.

Forero, José M. "Instrucción militar", Boletin Militar de Colombia, serie VI, vol. I, No. 1, Bogotá, enero de 1905.

MARquez, Eurípides. "El ejército colombiano y la obra realizada en él por las misiones militares chilenas", Revista del Ejército, Bogotá, No. 180-181 (junio-julio, 1927).

MEDina, José. Informe del Ministerio de Guerra a la Asamblea Nacional de 1910. Bogotá, s.p.i.

Ministerio de GuerRa. Informe al Congreso de 1914. Bogotá, Imprenta Nacional, 1914.

PAPA, José A. "La educación moral del soldado", Memorial del Estado Mayor, año XI, vol. 14, Bogotá, Talleres Gráficos del Ejército, 1921.

PARDo, Marco A. "De la educación moral del soldado", Memorial del Estado Mayor, año XII, vol. 15, Bogotá, Talleres Gráficos del Ejército, 1922.

----. Memorial del Estado Mayor, año $\mathrm{XI}$, vol. 14, Bogotá, Talleres Gráficos del Ejército, 1921.

Rojas, C. "Necesidad de un cuerpo de suboficiales instructores", 9, año III. cuaderno 1, Bogotá, Talleres del Estado Mayor, 1913.

\section{ARCHIVOS CONSULTADOS}

Archivo General de la Nación. Bogotá Colombia. AGN.

Archivo de la Presidencia de la República. Bogotá - Colombia. APR.

Archivo General del Ministerio de Defensa Bogotá - Colombia. ANAC.

Museo de la Escuela Militar de Cadetes. Bogotá - Colombia. MEMC.

Archivo Nacional de la Administración Central. Santiago de Chile-Chile. ANAC.

Archivo General del Ejército de Chile. Santiago de Chile-Chile. AGECH. 